\title{
Assessing local impacts of water use on human health: evaluation of water footprint models in the Province Punjab, Pakistan
}

\author{
Natalia Mikosch ${ }^{1}$ (I) $\cdot$ Markus Berger $^{1} \cdot$ Elena Huber $^{1} \cdot$ Matthias Finkbeiner $^{1}$
}

Received: 2 June 2020 / Accepted: 11 March 2021 / Published online: 31 March 2021

(c) The Author(s) 2021

\begin{abstract}
Purpose The water footprint (WF) method is widely applied to quantify water use along the life cycle of products and organizations and to evaluate the resulting impacts on human health. This study analyzes the cause-effect chains for the human health damage related to the water use on a local scale in the Province Punjab of Pakistan, evaluates their consistency with existing WF models, and provides recommendations for future model development.

Method Locally occurring cause-effect chains are analyzed based on site observations in Punjab and a literature review. Then, existing WF models are compared to the findings in the study area including their comprehensiveness (covered causeeffect chains), relevance (contribution of the modeled cause-effect chain to the total health damage), and representativeness (correspondence with the local cause-effect chain). Finally, recommendations for the development of new characterization models describing the local cause-effect chains are provided.

Results and discussion The cause-effect chains for the agricultural water deprivation include malnutrition due to reduced food availability and income loss as well as diseases resulting from the use of wastewater for irrigation, out of which only the first one is addressed by existing WF models. The cause-effect chain for the infectious diseases due to domestic water deprivation is associated primarily with the absence of water supply systems, while the linkage to the water consumption of a product system was not identified. The cause-effect chains related to the water pollution include the exposure via agricultural products, fish, and drinking water, all of which are reflected in existing impact assessment models. Including the groundwater compartment may increase the relevance of the model for the study area.

Conclusions Most cause-effect chains identified on the local scale are consistent with existing WF models. Modeling currently missing cause-effect chains for the impacts related to the income loss and wastewater usage for irrigation can enhance the assessment of the human health damage in water footprinting.
\end{abstract}

Keywords Water footprint $\cdot$ Human health damage $\cdot$ Impact assessment $\cdot$ Cause-effect chain $\cdot$ Water consumption $\cdot$ Water pollution

\section{Introduction}

The pressure on the resource water and associated risks for human well-being gained international attention recently (Hameeteman 2013; The World Bank 2019). According to UN-Water (2019), global water withdrawals are predicted to increase by up to $30 \%$ in the next decades, leading to

Communicated by Stephan Pfister.

Natalia Mikosch

natalia.mikosch@tu-berlin.de

1 Chair of Sustainable Engineering, Technische Universität Berlin, Straße des 17. Juni 135, Berlin 10623, Germany growing water scarcity and continuing water quality deterioration in the world's major river basins (UNEP 2016a). This trend can lead to a significant increase of impacts on human health, particularly in low-income countries, where unsafe water is responsible for over 6\% of the total Disability Adjusted Life Years (DALYs), the second highest health burden after underweight children (WHO 2009).

One of the methods describing this problem is the water footprint (WF), which quantifies water consumption and pollution along the products' supply chains (Hoekstra et al. 2011). During the past decade, WF method was enhanced to include the quantification of local consequences of the water use (ISO 2014) based on the life cycle assessment (LCA) methodology (ISO 2006a, b). Methods describing 
the impacts of water use address three areas of protection (AoPs): human health (Boulay et al. 2015), natural environment (Núñez et al. 2016), and resources (Pradinaud et al. 2019a, b). Further, they model impacts at different levels in the cause-effect chain. While midpoint methods (AWARE, WAVE, WSI, etc.) typically describe freshwater deprivation for other users in the middle of the cause-effect chain, endpoint models describe the resulting damages at the three AoPs. A detailed overview on existing methods can be found in review papers (Berger and Finkbeiner 2010; Kounina et al. 2013). This paper is dedicated to the AoP human health, leaving the midpoint results and two other AoPs out of the scope.

In water footprinting, human health damage is determined by multiplying water consumption and emission flows that affect water quality by the characterization factors (CFs), which reflect the severity of the resulting impacts in a certain region. The CFs originate from the characterization models that describe the cause-effect chains related to the water use. Over the past decade, several models were developed, which assess human health damage related to the freshwater use, e.g., due to malnutrition (Pfister et al. 2009; Boulay et al. 2011; Motoshita et al. 2014), infectious diseases (Boulay et al. 2011; Motoshita et al. 2011), and diseases attributed to toxicity (Rosenbaum et al. 2008).

The CFs provided by existing WF models are available usually with a spatial resolution at a water basin (midpoint) or country (endpoint) level. Nevertheless, the need for further regionalization to increase the reliability and representativeness of the results was emphasized by several authors (Patouillard et al. 2018; Frischknecht et al. 2019). Recent studies demonstrate that the midpoint results calculated with a higher spatial granularity (e.g., sub-basin (Núñez et al. 2015) and irrigation sub-divisions (Mikosch et al. 2020a)) significantly differ from the results provided by less regionalized models (e.g., 60\% higher water scarcity at a local level in Pakistan). In contrast, less attention was paid to the regionalization of the WF impact assessment models at the endpoint level, which are currently applied with the resolution on a country scale (e.g., Berger et al. (2012)). However, the extent of the human health damage may significantly vary between different regions within one country. The need for further regionalization of the model parameters and evaluation of the robustness of the cause-effect chain related to the malnutrition damage was addressed by the UNEP task force (UNEP 2016b). To address this gap, following steps need to be carried out: (1) evaluation whether existing global models are robust on a local scale, i.e., locally occurring impacts are reflected by modelled cause-effect chains, and (2) calculation of the CFs with a higher spatial resolution.

This study focuses on the first step introduce above. It aims at identifying local cause-effect chains associated with water consumption and pollution using the example of the province Punjab in Pakistan and analyzing how well these cause-effect chains can be reflected by existing impact assessment models. The analysis is based on the results obtained in the project "Reducing the water footprint of the global cotton-textile industry towards the UN Sustainable Development Goals" (InoCottonGROW) funded within the measure Global Resource Water (GRoW) by the German Federal Ministry for Education and Research (BMBF) (InoCottonGROW 2019). The aim of the project was to support sustainable water use along the cotton-textile value chain in Pakistan, one of the major suppliers of textile products for Germany. In collaboration with Pakistani partners, a detailed inventory of the local water consumption and pollution levels was conducted and optimization strategies to reduce the pressure on water resources in the study area were developed (Weber et al. 2019). For the quantification of the local impacts associated with the water use, the WF method was applied. The region-specific Water Scarcity Footprint (WSF) was calculated by means of spatially and temporally explicit water scarcity factors (Mikosch et al. 2020a). Finally, the consistency between locally occurring and existing global cause-effect chains was evaluated and new region-specific cause-effect chains were developed, which are presented in this publication.

This paper is structured as follows: the second section describes applied methodological procedure; Sect. 3 provides the results including the locally identified cause-effect chains and their comparison to the existing models; and in Sect. 4, recommendations for future model development are provided and transferability of the results to other world regions is discussed.

\section{Method}

\subsection{Nomenclature}

For consistency reasons, the following nomenclature is adopted throughout this article:

- Water use includes water withdrawal, discharge and release of emission flows, which lead to a change in water flows and/or quality (ISO 2014)

- Water consumption is a type of water use that leads to the removal of water from the drainage basin where it was withdrawn, e.g., through evapotranspiration or product integration (ISO 2014)

- The terms cause-effect chain and impact pathway are usually used as synonyms and represent an environmental mechanism from the intervention (water consumption or discharge of emissions flows) to the impacts on the AoPs (Rosenbaum et al. 2018). In this article, we use the term cause-effect chain when referring to the entire 
model from the intervention to the final impact (e.g., from agricultural water deprivation to malnutrition) and the term impact pathway for a single interlinkage within a cause-effect chain (e.g., yield loss due to agricultural water deprivation)

- The term chemical diseases is used based on the nomenclature introduced by Stanwell-Smith (2009) and includes the diseases attributed to the exposure to chemical pollutants in water bodies.

\subsection{Procedure}

The method applied in this study includes three main steps. During the first step, local cause-effect chains associated with the water use are analyzed. Based on the on-site communication and observations carried out during the field trips to Pakistan, local impacts are identified and causeeffect chains are developed. Two field trips to Pakistan, each 5 days long, were carried out in July 2017 and January 2019. The information on the local impacts associated with water consumption and pollution was collected during the participation in local conferences and accompanying workshops as well as during the field trips to the agricultural areas and textile mills. The following population groups were included in the discussions: researchers, members of a non-governmental organization, representatives of a ministry, farmers, and employees of the textile mills. An example of an identified impact is discoloration of the vegetables claimed by several farmers, who relate the impact to the polluted irrigation water. The cause-effect chain developed for this impact includes the discharge of untreated wastewater (mainly by the textile producing mills), pollution of freshwater bodies used for irrigation, accumulation of the contaminants in the vegetables, and finally human damage through the intake of food. To support and verify the findings gathered during the field trips, a literature review was conducted for the identified cause-effect chains. The publications describing the study area (Punjab) or Pakistan as a whole country were considered. The studies related to other regions of Pakistan (e.g., Karachi, Northern Pakistan) were excluded from the review, since the impacts and the cause-effect chain might strongly differ from the study area due to different geographic and socio-economic conditions. More details on the procedure and the results of the literature review are provided in Appendix A.1-A.4).

During the second step, the consistency between local and existing global cause-effect chains was evaluated by answering the following three questions:

1) If the cause-effect chains provided by existing models are comprehensive, i.e., cover all local cause-effect chains taking place in the study area
2) If the cause-effect chains provided by existing models are relevant, i.e., cover the local cause-effect chains with the highest damage to human health

3 ) If the cause-effect chains provided by existing models are representative for the study area, i.e., reflect the impact pathways occurring within the local cause-effect chains.

Finally, the results are summarized and practical recommendations for increasing the consistency between local and modeled cause-effect chains are provided (Fig. 1).

\subsection{Description of the study area}

Punjab is located in the eastern part of Pakistan on the border to India. With about 110 million citizens, it has more than half of Pakistan's total population (Bureau of Statistics 2018). The region is seasonally exposed to very high water scarcity, which is caused by arid climate conditions on the one hand and extensive usage of freshwater resources on the other. According to FAO (2020), over $80 \%$ of the locally available renewable water resources are already being used, with irrigated agriculture contributing to over $90 \%$ of total water withdrawals in the region. Growing population accompanied by increasing industrial and agricultural production leads to increasing pressure on and competition for the resource water. As a result, recent studies estimate that between 40 and $80 \%$ of all diseases in the region have a common origin, namely water scarcity and pollution (WWFPakistan 2007; Nabi et al. 2019).

The Province Punjab is the economically strongest province of Pakistan, with the agricultural sector and textile and leather manufacturing contributing mostly to its GDP. Over one-third of the total population in Pakistan is employed in the agricultural sector (Statista 2020). Two main industrial centres of Punjab - the cities Lahore and Faisalabad, account for one-fifth of the total wastewater flow recorded in the country, with less than $1 \%$ being treated in Lahore and $26 \%$ in Faisalabad. Industrial and domestic effluent is discharged into drain channels, which collect wastewater from urban areas and transport it to the rivers (WWF-Pakistan 2007).

In Punjab, almost $90 \%$ of the cropland is irrigated. The main water source for the agricultural production is the Ibis Basin Irrigation System (IBIS), which delivers water from the rivers to the fields through an extensive network of irrigation channels (FAO AQUASTAT 2011). To fulfil the growing demand for water caused by expanding agricultural production, groundwater abstractions are continuously increasing. The share of groundwater in the total irrigation water supply reaches over 60\% (Bureau of Statistics 2018). At the same time, wastewater irrigation is widely applied to mitigate water shortage. According to Ensink et al. (2005), 
Fig. 1 Methodological procedure

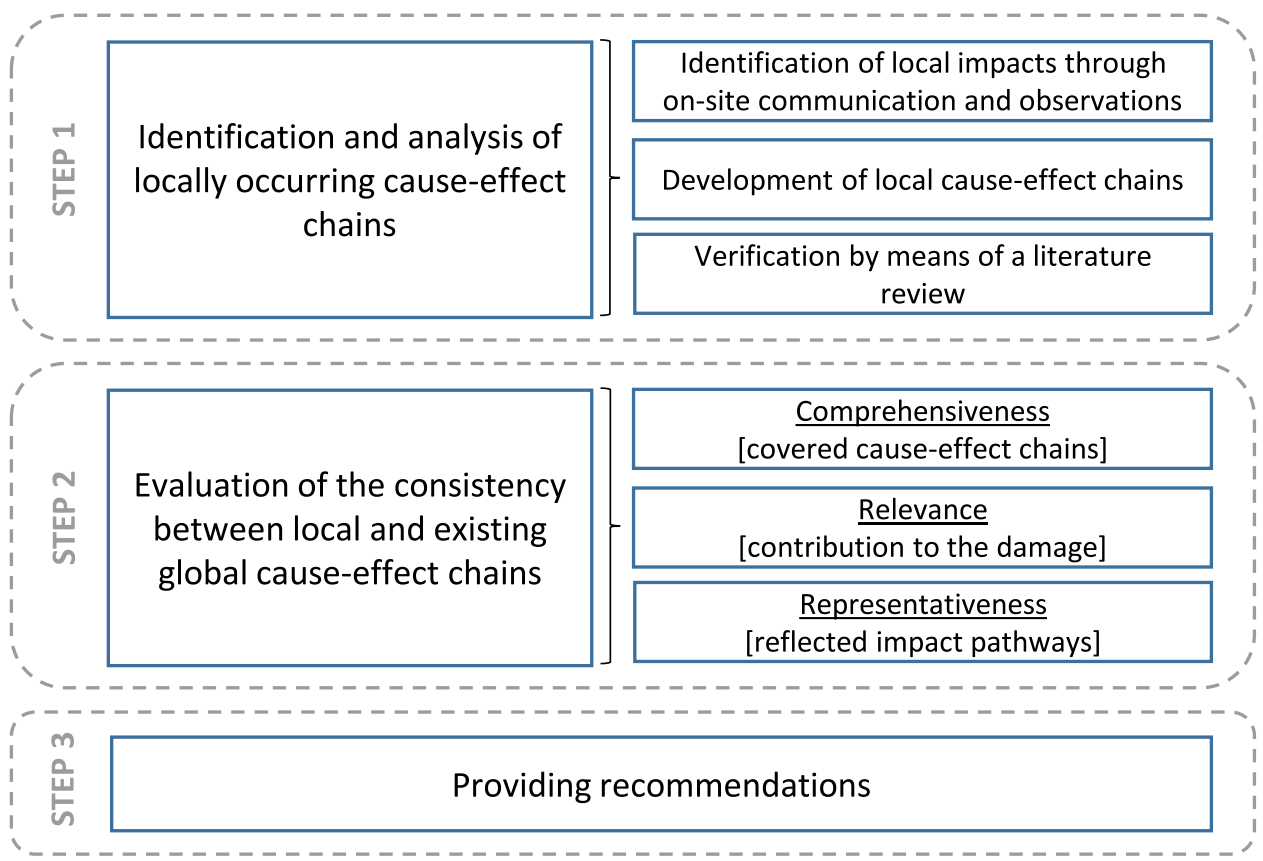

$25 \%$ of vegetables grown in Pakistan are irrigated with untreated wastewater (Fig. 2).

Agricultural production is divided in two seasons. The summer season kharif (May-October) is particularly hot with water scarcity levels reaching the maximum despite some increase in the rainfall during the monsoon period
(July-August). During this time, rice is cultivated in the northern, more water abundant areas of the province, while cotton and sugar cane are cultivated in the arid southern regions. During the winter season rabi (November-April), water scarcity reduces and such crops as wheat and fodder are cultivated (Mikosch et al. 2020a). In 2018, Pakistan

Fig. 2 Study area

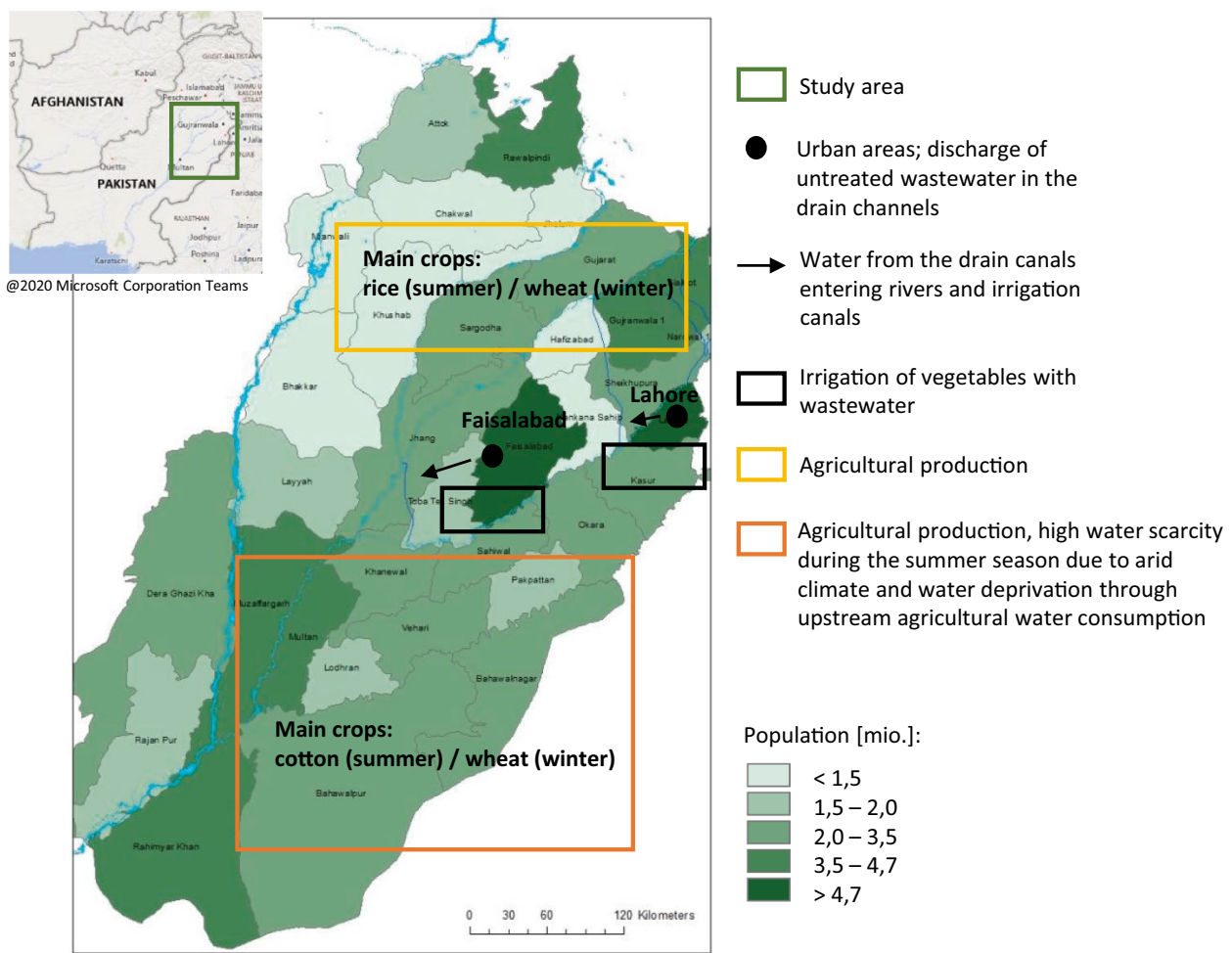


exported around 13 million tons of agricultural products, mainly rice (29\% of total exports) and wheat ( $22 \%$ of total exports) (Chantam House 2020). Still, more than $90 \%$ of produced wheat is consumed domestically (USDA 2020). Agricultural imports amounted to 6.5 tons in 2018, with palm oil (46\% of total imports) and soya beans ( $34 \%$ of total imports) as the main goods (Chantam House 2020).

According to WWF-Pakistan (2007), up to $40 \%$ of all registered diseases in Pakistan are attributed to unsafe water. Recent studies demonstrate increased concentrations of heavy metals in surface and groundwater as well as in vegetables (Mahmood and Malik 2014; Waseem et al. 2014), emphasizing the potential link to the wastewater discharged into the wastewater drains or used for irrigation (Manzoor et al. 2006). Domestic water supply is fulfilled by tap water, dug wells, hand, and motor pumps. Tap water originates from the groundwater reservoirs, which are located upstream of the cities. Surface water bodies (e.g., rivers and irrigation channels) are not used for the drinking water supply due to the high pollution levels. Nevertheless, around $1 \%$ of the domestic water is withdrawn from the surface water bodies and can be traced back to the poorest population groups, who do not have access to other water supply systems (Pakistan Bureau of Statistics 2016).

The prevalence of children malnutrition (underweight) varies from 18 up to 50\% in different districts of Punjab (Bureau of Statistics 2018). Wheat is the main staple food and covers up to $50 \%$ of total daily calorie intake, particularly for the poor population groups, followed by dairy (15\%) and oils (12\%) (Malik 2014).

\subsection{Cause-effect chains provided by existing WF models}

The WF method considers two types of water use: water consumption and water pollution (ISO 2014). The impacts calculated by WF originate from water deprivation (i.e., water scarcity footprint (WSF) or water availability footprint (WAF)) or intake of the contaminants (water degradation footprint (WDF) (Mikosch et al. 2020b)) and vary depending on the affected user groups. The latter include agriculture (irrigation water), domestic (water for drinking and sanitation), and aquaculture (fisheries) (Kounina et al. 2013; Motoshita et al. 2016).

\subsubsection{Agricultural water deprivation}

Existing WF models calculate agricultural water deprivation as a result of both water consumption (Pfister et al. 2009; Boulay et al. 2011; Motoshita et al. 2014) and pollution (Boulay et al. 2011). In the second case (water deprivation due to water pollution), the impact quantification is based on the assumption that emission flows lead to a reduction of water quality and, as a consequence, some users cannot use water, since their quality requirements are not fulfilled. The cause-effect chain for the agricultural water deprivation includes the loss of the food crops due to insufficient irrigation, resulting food shortage and subsequent reduced calorie intake, which finally leads to the malnutrition damage. The model of Motoshita et al. (2014) considers along with the inland food losses also the effect of the international trade with food commodities, which can mitigate the impacts of local food shortages. Based on this model, recently, a recommendation was provided for the quantification of the human health damage related to the agricultural water deprivation (UNEP 2016b). Existing model was slightly modified, e.g., for the food production loss, water withdrawal was changed to water consumption, adaptation capacity for middle income was adjusted and the CFs were provided with a higher spatial resolution at a watershed level. Since this model applies the same cause-effect chain as developed by Motoshita et al. (2014), in the following, the original paper will be referred to (Fig. 3).

\subsubsection{Domestic water deprivation}

The cause-effect chains for domestic water deprivation calculate human health damage due to the spread of
Fig. 3 Overview of the impact assessment approaches applied in water footprinting for the human health AoP (based on Boulay et al. (2015) and Mikosch et al. (2020b))

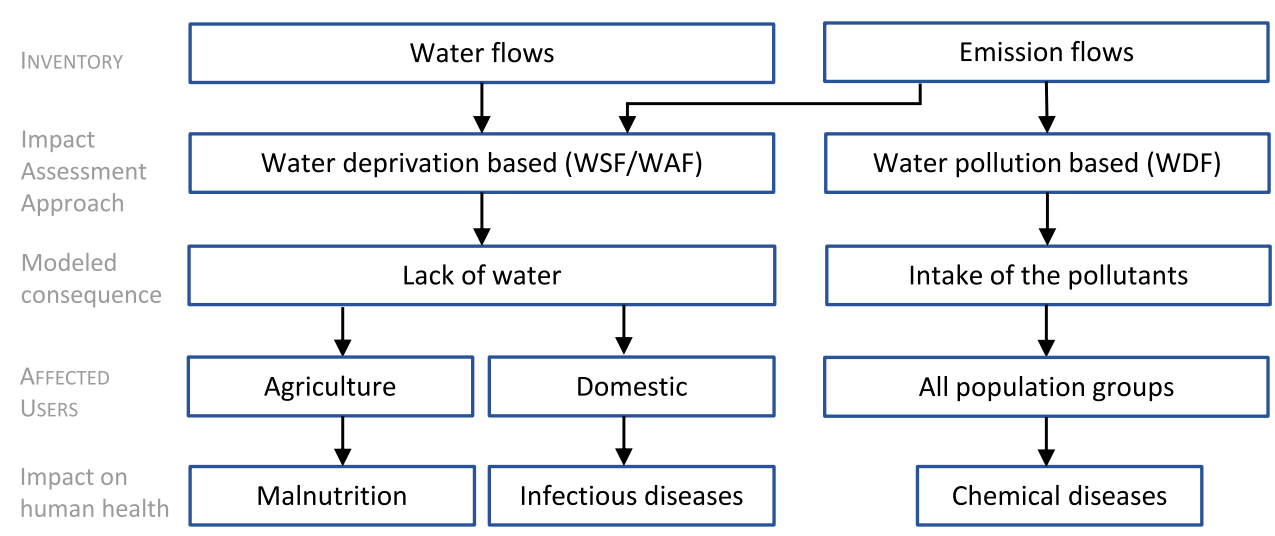


infectious diseases associated with the water shortage for drinking and sanitation (e.g., diarrheal disease). Same as for the agricultural water use, the cause-effect chains for the domestic water deprivation are modelled for both water consumption (Boulay et al. 2011; Motoshita et al. 2011) and pollution (Boulay et al. 2011). The model of Boulay et al. (2011) uses the threshold of 501 per capita and day to calculate water deficit for domestic use. The health damage is calculated by multiplying the water deficit by the health burden $\left(\mathrm{DALY} / \mathrm{m}^{3}\right)$, which was determined by the authors based on the data of the World Health Organization (WHO). Motoshita et al. (2011) quantify health damage based on reduced water accessibility, which is determined considering freshwater availability and supply (i.e., water supply systems).

The aforementioned models for the malnutrition impacts and infectious diseases introduce a physical factor (usually a water scarcity index (except the model of Motoshita et al. (2011) who uses the annual average temperature and a socioeconomic parameter) to reflect the severity of the impact depending on the local conditions. The socio-economic parameter reflects the ability of the population to mitigate the negative impacts associated with the water deprivation, e.g., through water treatment or desalination, and is also referred to as adaptation capacity (AC). The AC is adopted by the WF methods through the macro-economic parameters like Human Development Index (HDI) or per capita gross national income (GNI).

\subsubsection{Water pollution}

The WDF calculates the propagation of the emissions in the environment, the exposure of the recipients (population) to these emissions, and the resulting chemical diseases (Fig. 3). The most widely used model for this cause-effect chain is the USEtox model (Rosenbaum et al. 2008) for the carcinogenic and non-carcinogenic diseases related to chemical poisoning, e.g., via intake of heavy metals or organic pollutants. The human health damage is calculated by multiplying the emission flows by the fate (FF), exposure (XF), and effect factors (EF) (Rosenbaum et al. 2008). The fate factor is calculated based on the contaminants' propagation in and between different environmental compartments (e.g., freshwater, agricultural soil, and urban air) using a mechanistic multimedia model (Henderson et al. 2011). The exposure factor calculates the amount of the contaminants transported to the population through ingestion of drinking water (direct exposure) and food (indirect exposure) including agricultural products, meat, dairy, and fish (Rosenbaum et al. 2011). The effect factor calculates the resulting impact on the human health via the dose-response function and is not side-dependent (Rosenbaum et al. 2008).

\section{Results}

The results are presented in Table 1, which summarizes the analysis of the locally occurring cause-effect chains and their comparison to existing models including their comprehensiveness, relevance, and representativeness as described in the methodological part of this study.

\subsection{Water deprivation-related impacts}

\subsubsection{Agricultural water deprivation}

Local cause-effect chains. For the user group agriculture, two main local impacts associated with water deprivation were identified: (1) loss of the yield followed by the income reduction for the farmers and (2) accumulation of the contaminants in the food crops, when wastewater is used for irrigation to compensate for the water shortage.

The impacts related to the loss of the yield were addressed as relevant mainly for the southern areas of Punjab. The reasons for this are arid climate conditions and water deprivation, which occur due to overuse of the water resources on the upstream agricultural areas. The corresponding cause-effect chain was developed for the malnutrition damage. It includes the reduction of income, inability to purchase required amount of food (reduced purchasing power), insufficient calorie intake, and finally malnutrition (Fig. 4, CEC.1.1). To verify this cause-effect chain, eight studies that analyse malnutrition and food security issues in the study area were reviewed.

All studies address income loss as one of the major determinants for the food (in)security and malnutrition. Furthermore, three studies indicated water deprivation as a relevant factor for the income loss of the farmers. Additionally, four studies addressed the interlinkage between food availability (i.e., food production and stock) and food security. Finally, reduced food utilization due to insufficient intake of drinking water was addressed as a relevant factor, since water is necessary for human body for an efficient uptake and utilization of calories and nutrients (see Table 1 and Appendix A.1). It should be noted that the studies on children malnutrition were analyzed separately. These studies demonstrated that in the study area, mother's education plays the most important role in preventing children malnutrition followed by the income and socio-economic status of the household (Appendix A.1).

The cause-effect chain that describes reduced crop production and subsequent reduced food availability was taken over from existing models (Fig. 4, CEC.1.2). Although both cause-effect chains occur in the study area, the relevance of the CEC.1.2 is significantly lower compared to CEC.1.1, 


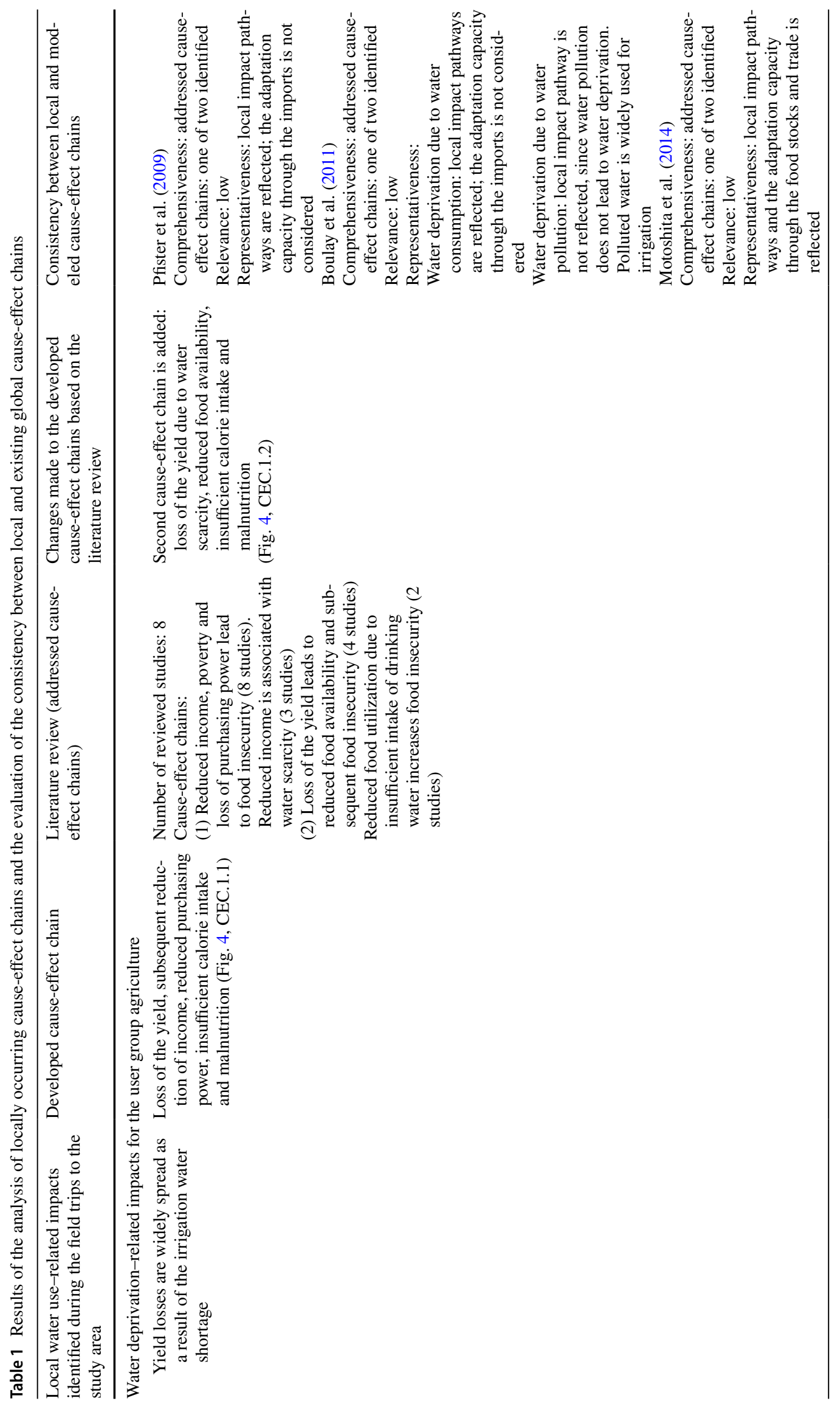




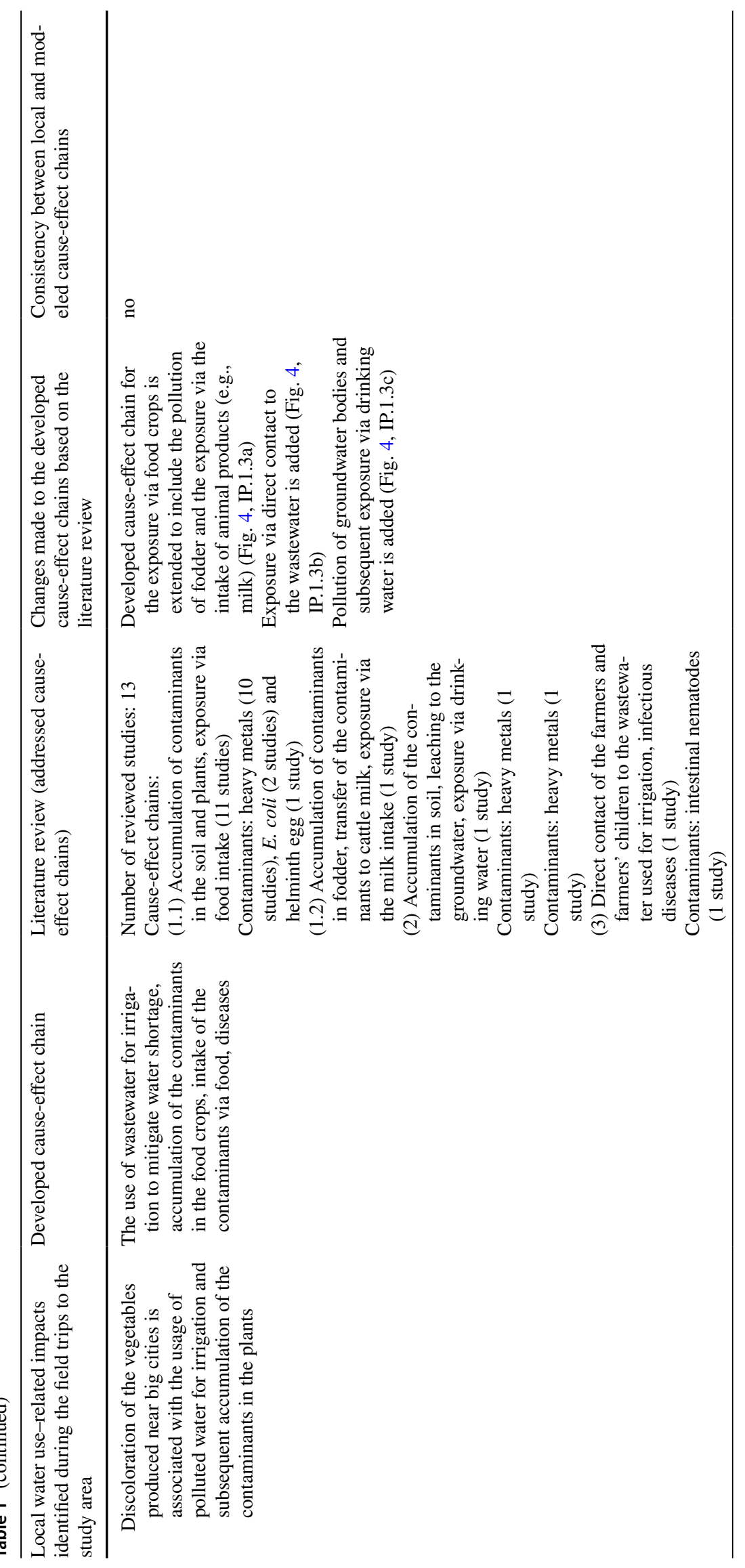




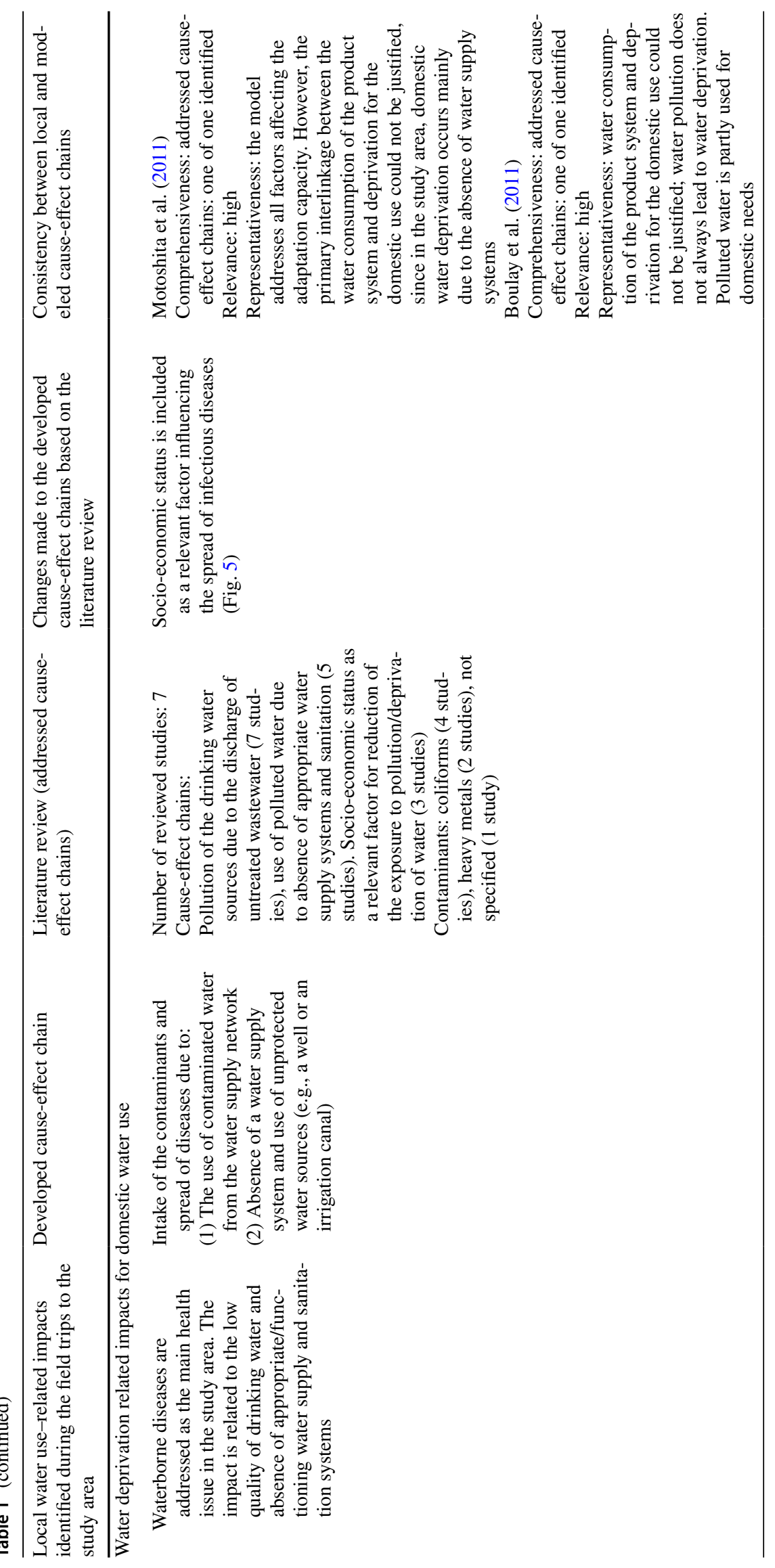




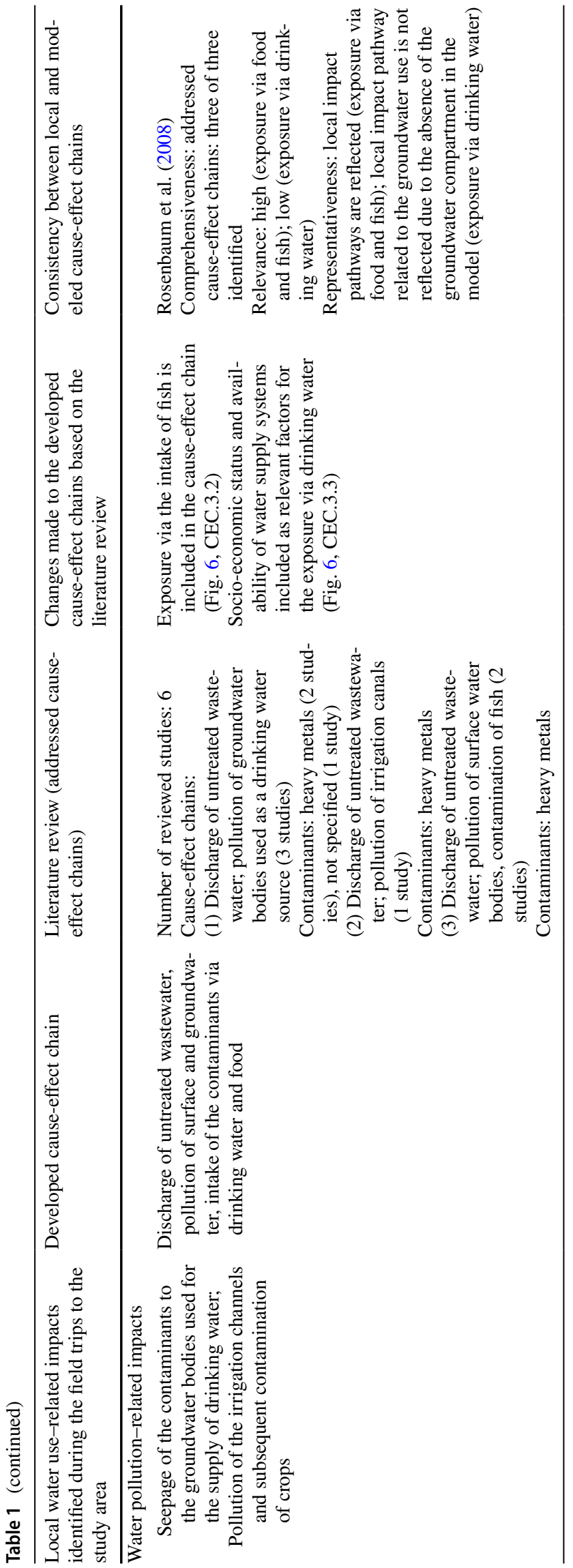

since in contrast to other regions of Pakistan, in Punjab, a surplus of food commodities is produced (Hussain and Routray 2012). Furthermore, water deprivation does not lead to a significant reduction in food availability. The reason for this lays in the cropping pattern applied in Punjab. As described in Sect. 2.3, wheat is grown during the less water scarce winter season. As a result, water deprivation affects food crops much less compared to the cash crops (mainly cotton) grown in arid southern areas of Punjab during the summer season. Furthermore, the lack of irrigation water for growing food crops, particularly vegetables, is often compensated by using wastewater (see Fig. 4, CEC.1.3). Finally, local shortfalls in the crop supply can be compensated by national or international trade.

The second locally identified impact is the accumulation of the contaminants in the food crops, which is related to the use of wastewater for irrigation to mitigate water shortages. This measure is applied in the areas, where groundwater does not fit for irrigation (e.g., due to high salinity level) and near to big cities, where significant amounts of wastewater are discharged. The developed cause-effect chain includes the usage of wastewater for irrigation, contamination of the food crops, and resulting damage due to the intake of the contaminants (Fig. 4, IP.1.3a). Overall, thirteen studies that analyse the impacts of the wastewater use for irrigation in the study area were reviewed (Appendix A.2). Most studies describe the exposure to heavy metals via food crops and vegetables. The transfer of heavy metals to livestock via polluted fodder and resulting intake of the contaminants from animal products (milk) was addressed in one study. Two further exposure pathways were addressed in the literature: via drinking water (one study) and via direct contact to the irrigation water (one study). All aforementioned exposure pathways were added to the developed cause-effect chain: pollution of fodder and intake of animal products (Fig. 4, IP.1.3a), direct contact to wastewater (Fig. 3, IP.1.3b), and intake of drinking water (Fig. 4, IP.1.3c).

Consistency between local and existing cause-effect chains. Existing WF models for the agricultural water deprivation address malnutrition impacts associated with reduced food availability (Fig. 4, CEC.1.2) (Pfister et al. 2009; Boulay et al. 2011; Motoshita et al. 2014). While Pfister et al. (2009) and Motoshita et al. (2014) calculate agricultural water deprivation associated with water consumption, the model of Boulay et al. (2011) implies water deprivation due to both water consumption and pollution (i.e., water is not used if it does not meet certain quality requirements). Furthermore, the model of Motoshita et al. (2014) considers the effects of the food trade by determining production and stocks as well as the import ratio of the food commodities in the analyzed region. Although this cause-effect chain is representative for the study area, it contributes to only a small share of the malnutrition damage, since as described above, income losses 


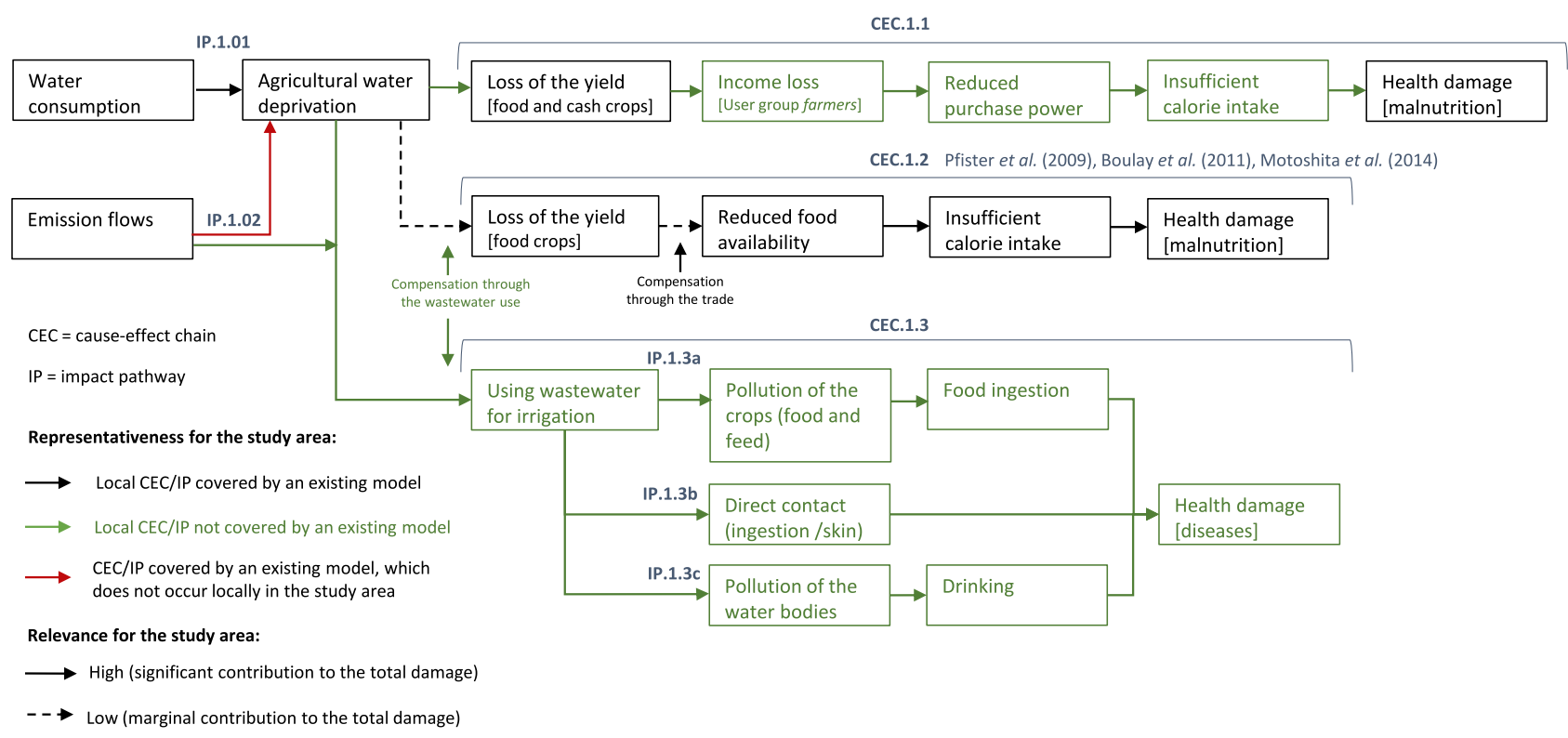

Fig. 4 Evaluation of the local and existing cause-effect chains for the agricultural water deprivation

are the main determinants of the malnutrition damage. Since polluted water is used for irrigation purposes in Punjab, the representativeness of the model for the agricultural water deprivation due to water pollution is evaluated as low for the study area (Fig. 4, IP.1.02).

The cause-effect chain for the usage of the wastewater due to the agricultural water deprivation is not addressed in any of existing WF models. It should be noted that this cause-effect chain relates to the water deprivation, i.e., lack of water leads to the use of the wastewater as an adaptation measure, which results in the intake of the pollutants. In contrast to the pollution based models, e.g., the USEtox model, the contaminants are discharged not by the product system, but originate from other local water users, e.g., domestic, industry, or other agricultural systems.

\subsubsection{Domestic water deprivation}

Local cause-effect chains. Waterborne infectious diseases were addressed in Punjab as the main health impact related to the domestic water use. The origin of these impacts lays in lack of hygiene and sanitation and insufficient water quality, which are associated mainly with the absence of appropriate water supply systems, i.e., water is delivered in insufficient amount and/or water is polluted, usually with pathogens. In contrast, water consumption of the upstream product systems does not contribute to the water deprivation of domestic water use as it occurs for the agricultural production. This can be explained by following two reasons. While for the agricultural production, surface water is supplied from the rivers via the irrigation channels, domestic water is sourced from the groundwater, which remains available throughout the year. At the same time, the second user of the groundwater in the study area, which is industry, withdraws relatively low amounts of water (compared to the agriculture) and therefore does not lead to the domestic water deprivation. Nevertheless, as demonstrated by WWF-Pakistan (2014) for the city Lahore, continuously increasing abstractions of groundwater may lead to lowering groundwater table and thus reduce the availability and accessibility of water. This may cause increasing competition for groundwater resources and result in water deprivation of domestic users. In this case, particularly vulnerable to water deprivation are the population groups who do not have access to water supply systems, but rely upon wells and self-installed water pumps.

The developed cause-effect chain is modeled for the impacts resulting from the absence of appropriate water supply systems and includes two impact pathways: (1) the use of unprotected water sources (Fig. 5, IP.2.03a) and the use of contaminated water from the water supply network (Fig. 5, IP.2.03b). Both impact pathways result in the diseases attributed to chemical and pathogen pollution, which originates mainly from the discharge of untreated wastewater (see Sect. 3.2 and Fig. 6). The conducted literature review for this cause-effect chain includes seven studies on the health damage related to drinking water. All studies address low quality of the drinking water due to the direct discharge of wastewater and seepage of the contaminants to the groundwater bodies used for drinking. Five studies addressed the relevance of the water supply systems with regard to the following factors: (1) damaged water supply systems contribute to the spread of pathogens and (2) the 


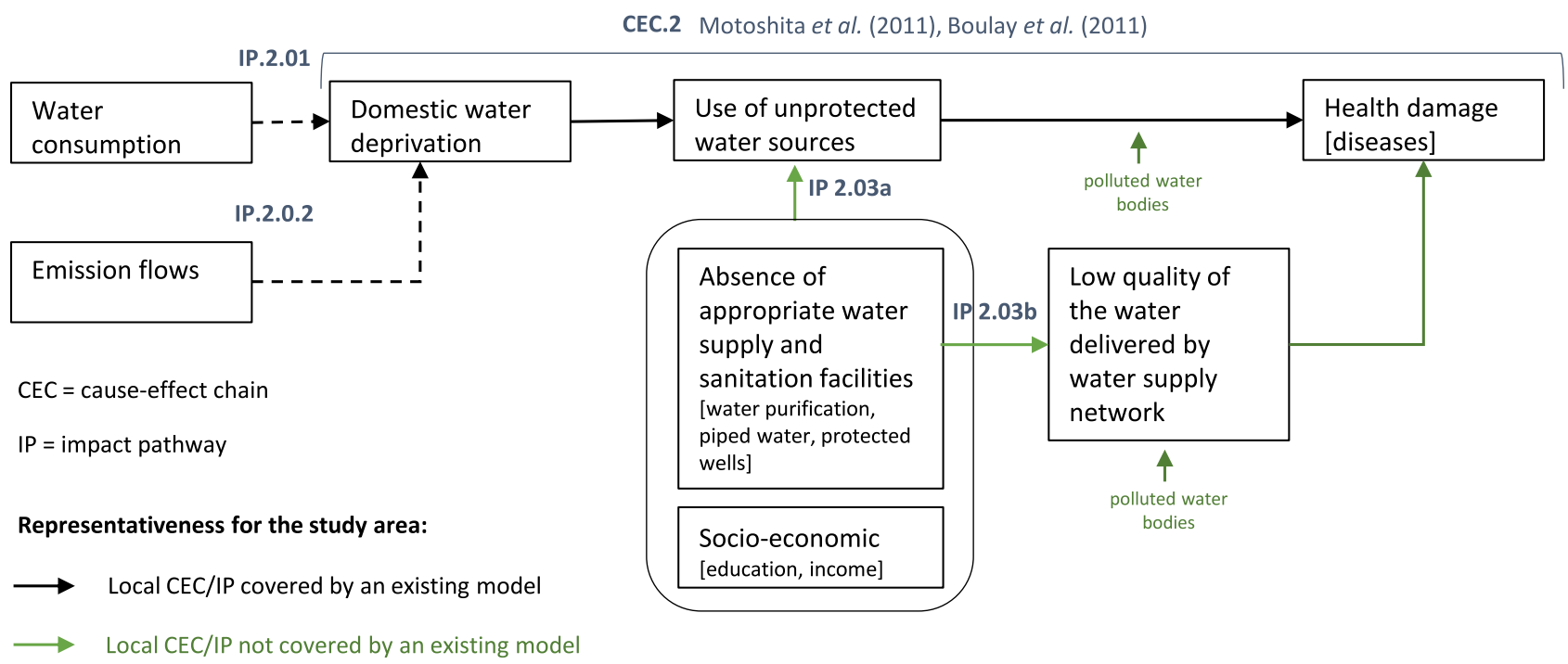

Relevance for the study area:

$\longrightarrow$ High (significant contribution to the total damage)

$-\rightarrow$ Low (marginal contribution to the total damage)

Fig. 5 Evaluation of the local and existing cause-effect chains for the domestic water deprivation

absence of domestic water supply leads to the use of unprotected water sources, e.g., wells or irrigation canals. Finally, three studies highlighted socio-economic status as a relevant factor for reduction of the vulnerability to water pollution and deprivation (see Table 1 and Appendix A.3). Based on these results, the socio-economic factor was included in the developed cause-effect chain.

Consistency between local and existing cause-effect chains. The cause-effect chain for the domestic water deprivation is covered by two existing models, which quantify health damage related to infectious diseases (Fig. 5, CEC.2). While the model of Motoshita et al. (2011) applies to the water deprivation associated with the water consumption (Fig. 5, IP.2.01), the model of Boulay et al. (2011) implies water deprivation due to both water consumption and pollution (Fig. 5, IP.2.02). Furthermore, the model of Motoshita et al. (2011) includes the factors house connection rate to water supply and house connection rate to sanitation, which are identified as significant for the infectious diseases in the current study. Since the cause-effect chain identified locally is covered by the aforementioned models, both models are evaluated as comprehensive and relevant for the study area. However, the representativeness of the interlinkage between domestic water deprivation and water consumption or pollution could not be justified for the study area. As described above, in Punjab, lack of water for domestic uses is strongly connected with the absence of the water supply systems. The same applies to the pollution related water deprivation.
Polluted water (e.g., from the irrigation channels) is utilized in households when other water sources are not available. Furthermore, polluted water is often used, when the contamination cannot be detected, e.g., through color or odor, which was also addressed in the study of Pradinaud et al. (2019b). In this case, emissions discharged to the freshwater will result in the diseases associated with the intake of the pollutants and not the water deprivation.

The direct impact of the water supply systems on domestic water deprivation is not addressed by any of the existing WF models. However, it should be noted that WF studies are usually carried out at a product level, where the product system does not have an impact on the water supply system (until it is not a part of it). In this case, water consumption of the product system does not contribute to the domestic water deprivation and the cause-effect chain has a low relevance for the WF.

\subsection{Water pollution related impacts}

Local cause-effect chains. In Punjab, water pollution associated with the discharge of untreated industrial and domestic wastewater is one of the main pressures on the environment and public health. Two impacts related to the water pollution were addressed in the study area: (1) contamination of the groundwater bodies used as a drinking water source through the seepage of wastewater and (2) pollution of the irrigation channels, which lead to the accumulation 


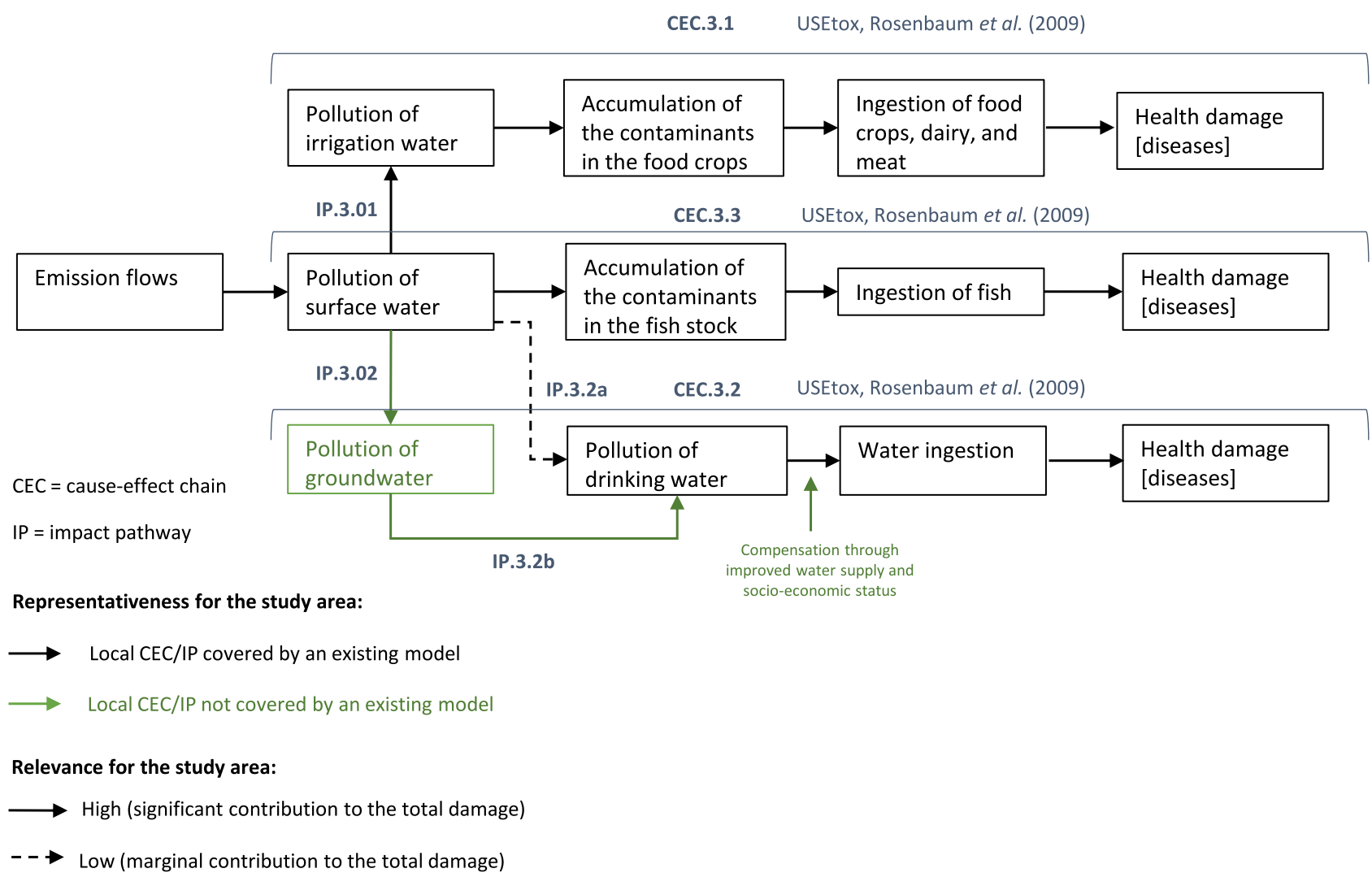

Fig. 6 Evaluation of the local and existing cause-effect chains for the water pollution

of the contaminants in the food crops. Based on these findings, the cause-effect chains were developed for the exposure via food crops (Fig. 6, CEC.3.1) and drinking water (Fig. 6, CEC.3.2). Overall, six studies that investigate the fate of and exposure to the contaminants discharged with the wastewater in the study area were reviewed (see Table 1 and Appendix A.4), out of which three studies address the seepage of the contaminants to the groundwater and one study analyses the pollution of irrigation canals. Furthermore, two studies demonstrate the accumulation of heavy metals in fish from the rivers Ravi and Chenab-the water bodies receiving the most wastewater in the study area. Therefore, the exposure pathway via fish intake was included in the cause-effect chain (Fig. 6, CEC.3.3). Furthermore, the factors socio-economic status and availability of water supply systems were included for the exposure via drinking water based on the results of the literature review conducted for the domestic water deprivation.

Consistency between local and existing cause-effect chains. All of the aforementioned cause-effect chains are reflected by the USEtox model (Rosenbaum et al. 2008). The local and modeled cause-effect chains for the exposure via food and fish intake are consistent. The modeled cause-effect chain for exposure via drinking water includes the spread of contaminants in the surface water, which is withdrawn afterwards for domestic usage (Fig. 6, IP.3.2a). However, as described above, in the study area, drinking water originates from the groundwater bodies. Therefore, this cause-effect chain has a low relevance for the study area, since it covers only a marginal share of the population. Since the USEtox model does not have a groundwater compartment (the causeeffect chain implies that all drinking water is supplied from the surface water bodies), the amount of contaminants taken up by the rest of the population is not addressed (Fig. 6, IP.3.2b).

It should be noted that the USEtox model calculates the impacts associated with the chemical pollution (heavy metals and organic substances). The pathogen pollution and associated impacts, in contrast, has been not addressed in water footprinting yet.

\section{Discussion and recommendations}

\subsection{Water deprivation-based models}

Agricultural water deprivation. We recommend including all three cause-effect chains for the agricultural water 
deprivation described in Sect. 3.1.1 to reflect the impacts on human health comprehensively (Fig. 4). To achieve this goal, the two cause-effect chains that are currently not addressed by the WF method need to be developed.

We recommend to include the following interlinkages in the cause-effect chain for the malnutrition impacts related to the loss of income: income loss associated with the loss of the yield, reduced purchase power (reduced food access), and insufficient calorie intake (see Fig. 4, CEC.1.1). The relationship between the water deprivation and income has already been addressed in several studies, e.g., by Calow et al. (2002) as economic return to water use, and by Namara et al. (2010), who described the linkage between the agricultural water use and poverty of rural population. FAO highlighted the particular vulnerability of the smallholder farmers in developing countries in this regard (FAO 2016). It should be noted that this cause-effect chain is applicable only for the user group farmers and therefore is relevant mainly for the countries with a large share of the population working in the agricultural sector. In contrast to the existing models, the proposed cause-effect chain is also representative for the production of non-food or cash crops, e.g., cotton, sugarcane, and coffee. While the loss of yield of these crops does not affect food availability, it can have a significant influence on the farmers' income and purchasing power.

We also recommend to model the cause-effect chain that describes the usage of the wastewater for irrigation purposes to mitigate water stress and the resulting health damage (Fig. 4, CEC.1.3). It is estimated that untreated or diluted wastewater is used on up to $7 \%$ of the world's irrigated area (UN-Water 2017); however, this impact pathway is not covered by any of the existing WF models. To reflect all potential impacts related to the wastewater usage, all three exposure pathways (indirect via food crops, indirect via drinking water, and direct via ingestion and/or skin) need to be included in the model. Furthermore, it should be considered that different types of contaminants are relevant for different exposure pathways. While the exposure via food leads to the uptake mainly of heavy metals (Khalid et al. 2018), pathogen pollution is particularly relevant for the direct and indirect exposure via water. Because in this cause-effect chain the health damage depends on the contaminants present in the irrigated water, it is essential to consider the rate of the safe water reuse (UN-Water 2020). This can be achieved either through using country-specific statistical data on the rates of wastewater safely treated or, if this data is not available, by introducing an adaptation capacity factor, e.g., based on the gross national income (GNI) as it is done in existing WF models.

Domestic water deprivation. As described in Sect. 3.1.2, in the study area, shortfalls in the domestic water availability and the spread of infectious diseases are caused mainly by the absence of water, sanitation, and hygiene (WASH) facilities and low water quality. In contrast, the contribution of water consumption of a product system as it is addressed in existing WF models could not be proved. Therefore, we recommend to further investigate on the role of the WASH in domestic water deprivation eventually giving it a greater weight in WF models.

\subsection{Water pollution-based models}

We recommend to consider the groundwater compartment to improve the representativeness of the cause-effect chain for the health damage associated with the exposure via drinking water (Fig. 6, CEC.3.2). Since the transfer of the contaminants (particularly heavy metals) to the groundwater compartment is strongly affected by the retention capacity of the soils and therefore site-dependent (Förstner and Wittmann 1979), establishing a global model that includes the fate of and exposure to the pollutants in the groundwater is challenging. Nevertheless, considering the groundwater compartment will significantly increase the share of the population in the study area covered by the model. This applies also to the neighboring regions, for example Bangladesh, where $98 \%$ of drinking water is supplied from the groundwater bodies (Bangladesh Burea of Statistics 2011).

Another relevant aspect identified with regard to the exposure via drinking water is availability of the water supply systems, since using improved water sources significantly reduces the exposure of the population. Therefore, we recommend including the parameters availability of water supply systems and socio-economic status in the cause-effect chain. This can be achieved by developing archetypes based on the rate of safe water use (i.e., from improved water sources) and the socio-economic development in a country or region, for example, based on the Human Development Index (HDI).

So far, human health damage related to the pathogen pollution has not been addressed in water footprinting. Nevertheless, waterborne diseases attributed to pathogens belong to the main health burden worldwide, particularly in developing countries (WHO 2009). For example, in Pakistan, more than 1.6 million DALYs are caused by the diarrhea diseases due to unsafe water, where the main source of the coliform bacteria is the seepage of the domestic wastewater (WWF-Pakistan 2007; Nabi et al. 2019). Therefore, we recommend to include pathogen pollution in the cause-effect chain modeled for the exposure via drinking water. For example, Harder et al. (2014) demonstrated the possibility to include pathogen risk in the LCA using the example of a wastewater treatment system. Among others, the authors considered the exposure pathways via drinking water and recreation, which are promising for integration into a WF model. 


\subsection{Transferability of the results to other world regions}

This study is dedicated to the analysis of the local causeeffect chains for the human health damage related to the water use in the province Punjab in Pakistan. It should be noted that the results including the identified cause-effect chains and evaluation of their consistency with existing WF models are applicable for this specific study area. Therefore, the findings of this study might be only partly representative for the rest of the world.

The cause-effect chain for the malnutrition impacts related to the income loss due to the yield losses is particularly relevant for the study area. The reason for this is, on one hand, a very high rate of the population working in the agricultural sector, and on the other hand, high poverty rates, which reach almost one-third of the population (Bureau of Statistics Punjab 2018). These two factors lead to a high economic dependence of the population on the yields. The risk of the income losses and poverty due to the yield losses has already been addressed in other studies, which highlight the particular vulnerability of small-holder farmers (Giordano et al. 2019) and the increasing pressure of climate change impacts (Vermeulen et al. 2012; FAO 2016). This indicates that the identified cause-effect chain may be applicable for other world regions, particularly low-income countries with a high percentage of the population working in the agricultural sector.

The relevance of the cause-effect chain describing the impacts related to the use of untreated wastewater for irrigation has also been identified for other regions, for example Iran (Qishlaqi et al. 2008), China (Khan et al. 2008) and India (Srinivasan and Reddy 2009). Due to the increasing demand for irrigation water, the role of wastewater in agricultural production may significantly increase in the future. Therefore, the identified cause-effect chain may gain importance for the assessment of human health damage, particularly for water-scarce regions with a low rate of safe wastewater treatment.

Still more research is needed to transfer the results to other world regions, since this study is based on the evidence from Pakistan and may not represent the cause-effect chains occurring in the rest of the world. With regard to the agricultural water deprivation, the relevance and representativeness of the three cause-effect chains (income loss, reduced food availability or compensation through wastewater usage) need to be verified for other regions. This may be challenging due to the variation of some key aspects of the agricultural sector in different countries, for example with regard to grown crops, population dependency on the agricultural sector, and availability of further compensation measures that mitigate water scarcity, e.g., storing rainwater in reservoirs or using desalinated seawater. Furthermore, the extent of the damage related to the wastewater use may significantly vary, since it depends on the contaminants type and concentration in the wastewater and thus is determined by the industrial sectors present in a country. Low availability of the inventory data for industrial water withdrawal and discharge (in particular missing water quality data) makes it difficult to model this cause-effect chain.

As described in Sect. 4.2, including groundwater compartment in the cause-effect chain for the water pollution can increase representativeness of the exposure pathway via drinking for the regions where drinking water is supplied from groundwater bodies. However, proposed cause-effect chain is not applicable for the regions where the groundwater body used for drinking is spatially separated from the source of pollution or protected from the contaminants. These aspects should be considered when evaluating the representativeness of the cause-effect chain for other world regions.

\subsection{Applicability of LCA models on a local scale}

The need for conducting spatially differentiated life cycle impact assessment (LCIA) has already been addressed in the late 1990s in the study of Potting and Hauschild (1997), who highlighted the importance of spatial information in characterization models describing the cause-effect chains for impact categories that do not have a global nature. Currently, several case studies and recommendations for the regionalization of the life cycle inventory and LCIA models are provided (Mutel et al. 2018; Patouillard et al. 2018). Nevertheless, the level of detail that is achievable and meaningful for LCA, i.e., the boundary between LCA and Environmental Impact Assessment (EIA), is currently not clear. Potting and Hauschild (1997) highlighted that the role of LCA is comparing and optimizing the full life cycles of products rather than evaluating the risk from a single local source. Therefore, the authors proposed to limit the efforts for the spatially explicit analysis to the processes with (1) a high contribution to the total impact and (2) a high relevance of local impacts (Potting and Hauschild 2006). Still, determining optimal spatial resolution and evaluating potential tradeoffs between the level of detail and completeness of scope remains challenging for LCA practitioners.

\section{Conclusions}

The current study analyzes local cause-effect chains for the human health damage assessment related to water use in the Province Punjab of Pakistan. Furthermore, it evaluates how far these cause-effect chains can be reflected by existing WF models in regard to their comprehensiveness (covered cause-effect chains), relevance (contribution of the modeled 
cause-effect chain to the total health damage), and representativeness (correspondence with the local cause-effect chain).

Overall, seven cause-effect chains for the human health damage related to water use were identified in the study area. Three local cause-effect chains are caused by agricultural water deprivation: (1) malnutrition damage due to income loss, (2) malnutrition damage due to reduced food availability, and (3) diseases resulting from the wastewater use for irrigation. Only the second one is addressed by existing WF models. Considering increasing water scarcity and growing food demand worldwide, all identified cause-effect chains may gain importance in the next decades and should be included in water footprinting. The cause-effect chain for the infectious diseases due to domestic water deprivation (4) is attributed to the lack of water supply systems rather than water consumption of a product system as it is addressed by existing WF models. Therefore, its representativeness for other world regions should be investigated. Local causeeffect chains for the water pollution related impacts include the intake of pollutants via agricultural products (5), fish (6), and drinking water (7), all of which are reflected by existing impact assessment models. Including the groundwater compartment in characterization models for the exposure via drinking water could increase the representativeness of the damage assessment in the study area.

In light of growing water scarcity and pollution levels worldwide, the importance of the WF as a tool to quantify impacts of water use on human health in global supply chains is increasing. In this regard, it is essential to develop robust models describing relevant cause-effect chains in order to provide support for decision-makers in policy and industry.

Supplementary Information The online version contains supplementary material available at https://doi.org/10.1007/s11367-021-01888-z.

Acknowledgements The authors would like to thank the InoCottonGROW project team for the helpful discussions and feedback. We also would like to acknowledge the coordination activities of Frank-Andreas Weber within the project InoCottonGROW, particularly the organization of the field-trips to Pakistan. Finally, we thank Laurine Sadetzky for her support in conducting the literature review for this study.

Funding Open Access funding enabled and organized by Projekt DEAL. This study was conducted within the research project InoCottonGROW funded by the German Federal Ministry of Education and Research (BMBF), funding measure "Water as a global resource (GRoW)," grant number 02WGR1422B. The Federal Ministry of Education and Research provided the financial support.

Open Access This article is licensed under a Creative Commons Attribution 4.0 International License, which permits use, sharing, adaptation, distribution and reproduction in any medium or format, as long as you give appropriate credit to the original author(s) and the source, provide a link to the Creative Commons licence, and indicate if changes were made. The images or other third party material in this article are included in the article's Creative Commons licence, unless indicated otherwise in a credit line to the material. If material is not included in the article's Creative Commons licence and your intended use is not permitted by statutory regulation or exceeds the permitted use, you will need to obtain permission directly from the copyright holder. To view a copy of this licence, visit http://creativecommons.org/licenses/by/4.0/.

\section{References}

Bangladesh Burea of Statistics (2011) Bangladesh National Drinking Water Quality Survey of 2009. Available at: https://washdata.org/ sites/default/files/documents/reports/2019-06/Bangladesh-2009MICS-water-quality-report.pdf

Berger M, Finkbeiner M (2010) Water footprinting: how to address water use in life cycle assessment? Sustainability 2(4):919-944. https://doi.org/10.3390/su2040919

Berger M, Warsen J, Krinke S, Bach V, Finkbeiner M (2012) Water footprint of European cars: potential impacts of water consumption along automobile life cycles. Environ Sci Technol 46(7):4091-4099. https://doi.org/10.1021/es2040043

Boulay A-M, Bulle C, Bayart J-B, Deschênes L, Margni M (2011) Regional characterization of freshwater use in LCA: modeling direct impacts on human health. Environ Sci Technol 45(20):8948-8957. https://doi.org/10.1021/es1030883

Boulay A-M, Motoshita M, Pfister S, Bulle C, Muñoz I, Franceschini $\mathrm{H}$ et al (2015) Analysis of water use impact assessment methods (part A): evaluation of modeling choices based on a quantitative comparison of scarcity and human health indicators. Int J Life Cycle Assess 20(1):139-160. https://doi.org/10.1007/ s11367-014-0814-2

Bureau of Statistics (2018) Punjab Development Statistics 2017. Lahore, Pakistan

Bureau of Statistics Punjab (2018) Punjab. Survey Findings Report. Multiple Indicator Survey 2017-18. Lahore, Pakistan

Calow R, MacDonald A, Nicol A, Robins N, Kebede S (2002) The struggle for water. Drought, water security and rural lifelihoods. British Geological Survey Commissioned Report, CR/02/226N. Nottingham

Chantam House (2020) resourcetrade.earth. Available at: https:// resourcetrade.earth/data?year $=2018 \&$ exporter $=586 \&$ category $=$ $1 \&$ units=weight(Accessed: 8 September 2020)

Ensink JHJ, van der Hoek W, Mukhtar M, Tahir Z, Amerasinghe FP (2005) 'High risk of hookworm infection among wastewater farmers in Pakistan', Trans. R. Soc. Trop. Med. Hyg. Oxford Academic, 99(11), pp. 809-818. https://doi.org/10.1016/j. trstmh.2005.01.005

FAO (2016) The state of food and agriculture. Rome, Italy, Climate Change, Agriculture and Food Security

FAO (2020) AQUASTAT. Pakistan: agricultural water withdrawal. Available at: http://www.fao.org/nr/water/aquastat/data/query/ results.html (Accessed: 19 March 2020)

FAO AQUASTAT (2011) Irrigation in Southern and Eastern Asia in figures. Available at: http://www.fao.org/nr/water/aquastat/ countries_regions/PAK/PAK-CP_eng.pdf

Förstner U, Wittmann GTW (1979) 'Metal transfer between solid and aqueous phases, in Met Pollut Aquat Environ. Berlin, Heidelberg: Springer, pp. 197-270. https://doi.org/10.1007/ 978-3-642-96511-1_5

Frischknecht R, Pfister S, Bunsen J, Haas A, Känzig J, Kilga M (2019) 'Regionalization in LCA: current status in concepts, software and databases - 69th LCA forum, Swiss Federal Institute of Technology, Zurich, 13 September, 2018', in Int. J. Life Cycle Assess. Springer Verlag, pp. 364-369. https://doi.org/10. 1007/s11367-018-1559-0 
Giordano M, Barron J, Ünver O (2019) Water scarcity and challenges for smallholder agriculture, in Sustain. Food Agric. Elsevier, pp. 75-94. https://doi.org/10.1016/b978-0-12-812134-4.00005-4

Hameeteman E (2013) Future water (in)security: facts, figures, and predictions. Belgium, Brussels

Harder R, Heimersson S, Svanström M, Peters GM (2014) Including pathogen risk in life cycle assessment of wastewater management. 1. Estimating the burden of disease associated with pathogens. Environ Sci Technol American Chemical Society 48(16):9438-9445. https://doi.org/10.1021/es501480q

Henderson AD, Hauschild MZ, Van De Meent D, Huijbregts MAJ, Larsen HF, Margni M et al (2011) USEtox fate and ecotoxicity factors for comparative assessment of toxic emissions in life cycle analysis: sensitivity to key chemical properties. Int J Life Cycle Assess 16(8):701-709. https://doi.org/10.1007/ s11367-011-0294-6

Hoekstra AY, Chapagain AK, Aldaya MM (2011) The water footprint assessment manual - setting the global standard. London, Washington, DC

Hussain A, Routray JK (2012) Status and factors of food security in Pakistan. Int J Dev Issues 11(2):164-185. https://doi.org/10.1108/ 14468951211241146

InoCottonGROW (2019) InoCottonGROW. Available at: https://www. inocottongrow.net/

ISO (2006a) Environmental management - life cycle assessment principles and framework. International Organization for Standardization, Ed. Geneva, Switzerland

ISO (2006b) Environmental management - life cycle assessment - requirements and guidelines. International Organization for Standardization, Ed. Geneva, Switzerland

ISO (2014) Water footprint - principles, requirements and guidance. International Organization for Standardization, Ed. Geneva, Switzerland

Khalid S, Shahid M, Natasha Bibi I, Sarwar T, Shah AH, (2018) A review of environmental contamination and health risk assessment of wastewater use for crop irrigation with a focus on low and highincome countries, Int. J. Environ. Res. Public Health. MDPI AG, 15(5). https://doi.org/10.3390/ijerph15050895

Khan S, Cao Q, Zheng YM, Huang YZ, Zhu YG (2008) Health risks of heavy metals in contaminated soils and food crops irrigated with wastewater in Beijing, China. Environ Pollut Elsevier 152(3):686692. https://doi.org/10.1016/j.envpol.2007.06.056

Kounina A, Margni M, Bayart J-B, Boulay A-M, Berger M, Bulle C et al (2013) Review of methods addressing freshwater use in life cycle inventory and impact assessment. Int J Life Cycle Assess 18(3):707-721. https://doi.org/10.1007/s11367-012-0519-3

Mahmood A, Malik RN (2014) Human health risk assessment of heavy metals via consumption of contaminated vegetables collected from different irrigation sources in Lahore, Pakistan. Arab J Chem Elsevier 7(1):91-99. https://doi.org/10.1016/J.ARABJC. 2013.07.002

Malik SJ (2014) Remarks on food security: international experience and cooperation. Available at: https://www.sdpi.org/sdc/presentationsdc/Sohail-Malik_IPC.pdf

Manzoor S, Shah MH, Shaheen N, Khalique A, Jaffar M (2006) Multivariate analysis of trace metals in textile effluents in relation to soil and groundwater. J Hazard Mater 137(1):31-37. https://doi. org/10.1016/j.jhazmat.2006.01.077

Mikosch N, Becker R, Schelter L, Berger M, Usman M, Finkbeiner M (2020a) High resolution water scarcity analysis for cotton cultivation areas in Punjab, Pakistan, Ecol. Indic. Elsevier, 109(105852). https://doi.org/10.1016/J.ECOLIND.2019.105852

Mikosch N, Berger M, Finkbeiner M (2020b) Addressing water quality in water footprinting: current status, methods and limitations. Int. J. Life Cycle Assess. Springer Science and Business
Media Deutschland GmbH, pp. 157-174. https://doi.org/10.1007/ s11367-020-01838-1

Motoshita M, Boulay AM, Pfister S, Benini L, de Figueirêdo MCB, Gheewala SH (2016) Water use related impacts: water scarcity and human health effects, in Frischknecht, R. and Jolliet, O. (eds) Glob. Guid. Life Cycle Impact Assess. Indic. Vol. 1. Paris, France: UNEP/SETAC Life Cycle Initiative, pp. 116-123

Motoshita M, Itsubo N, Inaba A (2011) Development of impact factors on damage to health by infectious diseases caused by domestic water scarcity. Int J Life Cycle Assess 16(1):65-73. https://doi. org/10.1007/s11367-010-0236-8

Motoshita M, Ono Y, Pfister S, Boulay AM, Berger M, Nansai K (2014) Consistent characterisation factors at midpoint and endpoint relevant to agricultural water scarcity arising from freshwater consumption, Int. J. Life Cycle Assess. Springer Berlin Heidelberg, 23(12), pp. 2276-2287. https://doi.org/10. 1007/s11367-014-0811-5

Mutel C, Liao X, Patouillard L, Bare J, Fantke P, Frischknecht $\mathrm{R}$ (2018) Overview and recommendations for regionalized life cycle impact assessment, Int. J. Life Cycle Assess. The International Journal of Life Cycle Assessment, pp. 856-865. https:// doi.org/10.1007/s11367-018-1539-4

Nabi G, Ali M, Khan S, Kumar S (2019) The crisis of water shortage and pollution in Pakistan: risk to public health, biodiversity, and ecosystem, Environ Sci Pollut Res. Springer Verlag, pp. 10443-10445. https://doi.org/10.1007/s11356-019-04483-w

Namara RE, Hanjra MA, Castillo GE, Ravnborg HM, Smith L, Van Koppen B (2010) Agricultural water management and poverty linkages. Agric Water Manag Elsevier 97(4):520-527. https:// doi.org/10.1016/j.agwat.2009.05.007

Núñez M, Bouchard CR, Bulle C, Boulay AM, Margni M (2016) 'Critical analysis of life cycle impact assessment methods addressing consequences of freshwater use on ecosystems and recommendations for future method development', Int. J. Life Cycle Assess. Springer Verlag, pp. 1799-1815. https://doi.org/ 10.1007/s11367-016-1127-4

Núñez M, Pfister S, Vargas M, Antón A (2015) Spatial and temporal specific characterisation factors for water use impact assessment in Spain. Int J Life Cycle Assess 20(1):128-138. https://doi.org/ 10.1007/s11367-014-0803-5

Pakistan Bureau of Statistics (2016) Pakistan Social and Living Standards Measurement Survey (2015-15). Islamabad

Patouillard L, Bulle C, Querleu C, Maxime D, Osset P, Margni M (2018) Critical review and practical recommendations to integrate the spatial dimension into life cycle assessment. J Clean Prod Elsevier Ltd 177:398-412. https://doi.org/10.1016/j.jclepro. 2017.12.192

Pfister S, Koehler A, Hellweg S (2009) Assessing the environmental impact of freshwater consumption in life cycle assessment. Environ Sci Technol 43(11):4098-4104. https://doi.org/10. 1021/es802423e

Potting J, Hauschild M (1997) Predicted environmental impact and expected occurrence of actual environmental impact. Int J Life Cycle Assess 2(4):209-216

Potting J, Hauschild MZ (2006) 'Spatial differentiation in life cycle impact assessment: a decade of method development to increase the environmental realism of LCIA', Int. J. Life Cycle Assess. Springer, pp. 11-13. https://doi.org/10.1065/lca2006.04.005

Pradinaud C, Northey S, Amor B, Bare J, Benini L, Berger M et al (2019a) Defining freshwater as a natural resource: a framework linking water use to the area of protection natural resources. Int J Life Cycle Assess Springer Verlag 24(5):960-974. https://doi. org/10.1007/s11367-018-1543-8

Pradinaud C, Núñez M, Roux P, Junqua G, Rosenbaum RK (2019b) The issue of considering water quality in life cycle assessment 
of water use. Int J Life Cycle Assess Springer Verlag 24(3):590603. https://doi.org/10.1007/s11367-018-1473-5

Qishlaqi A, Moore F, Forghani G (2008) Impact of untreated wastewater irrigation on soils and crops in Shiraz suburban area, SW Iran. Environ Monit Assess Springer 141(1-3):257-273. https:// doi.org/10.1007/s10661-007-9893-x

Rosenbaum RK, Bachmann TM, Gold LS, Huijbregts MA, Jolliet O, Juraske R et al (2008) USEtox - The UNEP-SETAC toxicity model: recommended characterisation factors for human toxicity and freshwater ecotoxicity in life cycle impact assessment. Int J Life Cycle Assess 13(7):532-546. https://doi.org/10.1007/ s11367-008-0038-4

Rosenbaum RK, Hauschild MZ, Boulay AM, Fantke P, Laurent A, Núñez M (2018) Life cycle impact assessment, in Hauschild, MZ, Rosenbaum RK, Olsen SI. (eds) Life cycle assessment. Theory Pract. Springer International Publishing AG, pp. 167270. https://doi.org/10.1007/978-3-319-56475-3_10

Rosenbaum RK, Huijbregts MAJ, Henderson AD, Margni M, McKone TE, Van De Meent D et al (2011) USEtox human exposure and toxicity factors for comparative assessment of toxic emissions in life cycle analysis: sensitivity to key chemical properties. Int J Life Cycle Assess 16(8):710-727. https://doi.org/10.1007/ s11367-011-0316-4

Srinivasan JT, Reddy VR (2009) Impact of irrigation water quality on human health: a case study in India. Ecol Econ Elsevier 68(11):2800-2807. https://doi.org/10.1016/j.ecolecon.2009.04. 019

Stanwell-Smith R (2009) Classification of water-related disease, in Grabow, W. O. (ed.) Water heal. Oxford, United Kingdom: EOLSS Publishers/UNESCO

Statista (2020) Pakistan: distribution of employment by economic sector from 2009 to 2019. Available at: https://www.statista.com/ statistics/383781/employment-by-economic-sector-in-pakistan/ (Accessed: 8 September 2020)

The World Bank (2019) Quality unknown. Washington, USA, The invisible water crisis. https://doi.org/10.1596/978-1-4648-1459-4

UN-Water (2017) The United Nations World Water Development Report 2017 Facts and Figures Perugia, Italy

UN-Water (2019) The United Nations World Water Development Report 2019. Leaving no one behind, Paris, France
UN-Water (2020) The United Nations World Water Development Report 2020. Water and Climate Change, Paris, France

UNEP (2016a) A snapshot of the world's water quality: towards a global assessment. United Nations Environmental Programme, Nairobi, Kenya

UNEP (2016b) Global guidance for life cycle impact assessment indicators. Volume 1. Available at: https://www.lifecycleinitiative.org/ training-resources/global-guidance-lcia-indicators-v-1/

USDA (2020) Grain and feed annual. Islamabad, Pakistan. Available at: https://apps.fas.usda.gov/newgainapi/api/Report/ DownloadReportByFileName? fileName $=$ Grain and Feed Annual_Islamabad_Pakistan_04-01-2020

Vermeulen S, Zougmoré R, Wollenberg E, Thornton P, Nelson G, Kristjanson P et al (2012) Climate change, agriculture and food security: a global partnership to link research and action for lowincome agricultural producers and consumers. Curr Opin Environ Sustain Elsevier 4(1):128-133. https://doi.org/10.1016/j.cosust. 2011.12.004

Waseem A, Arshad J, Iqbal F, Sajjad A, Mehmood Z, Murtaza G (2014) 'Pollution status of Pakistan: a retrospective review on heavy metal contamination of water, soil, and vegetables', Biomed Res. Int 2014:1-29. https://doi.org/10.1155/2014/813206

Weber FA, Usman M, Tischbein B, Baggi C, Baumann, C., Becker $\mathrm{R}$, (2019) 'InoCottonGRoW: reducing the water footprint of the global cotton-textile industry towards the UN sustainable development goals', in Proc. GRoW Midterm Conf. - Glob. Anal. local Solut. Sustain. water Resour. Manag. Frankfurt am Main, pp. $32-35$

WHO (2009) Global health risks: mortality and burden of disease attributable to selected major risks. Bull World Health Organ 87:646-646. https://doi.org/10.2471/BLT.09.070565

WWF-Pakistan (2007) Pakistan's waters at risk water \& health related issues in Pakistan \& key recommendations Lahore, Pakistan

WWF-Pakistan (2014) Situation analysis of the water resources of Lahore, Pakistan establishing a case for water stewardship https:// doi.org/10.13140/2.1.4000.6728

Publisher's Note Springer Nature remains neutral with regard to jurisdictional claims in published maps and institutional affiliations. 